for example, that the conventions which governed the operation of the Anglo-Saxon vengeance group were rules which must lead to peace rather than anarchic war. Similarly, he demonstrates that in many different African societies there is a wide range of situations in which the hatred generated by structures of authority is quite explicit. Rebellion against legitimate office-holders is almost institutionalized. Paradoxical perhaps, and yet clearly the public expression of hatred is also a public assertion of the high value of that which is hated. The Barotse, we are told, "state explicitly that it is the lot of leaders to be hated, because they are the Law itself".

With regard to the family, Prof. Gluckman argues that, where relationship is effectively maintained among a wide circle of kinsmen, then husband and wife must of necessity be somewhat estranged. Even malice is claimed to have a positive value; witch. craft accusations, by projecting the responsibility for evil on to the scapegoat witch, permit the ordinary man to retain his faith in the moral virtue of brotherly love even when his own daily actions are anything but kindly.

In all these cases there is the common theme that it is an essential feature of the working of any social system that the 'friends' of one context should be the 'enemies' of another. It is the divided loyalties of the individual resulting from this contradiction which makes peaceful co-operation humanly possible. This, it is maintained, is true even in the context of the colour bar of South African native reserves. It is all very ingenious; such an analysis has many applications much nearer home than South Africa. $A$ useful and well-selected reading list has been added to the text of the original spoken lectures.

E. R. LEACH

\section{DICTIONARY OF TELEVISION AND RADAR TERMS}

Elsevier's Dictionary of Television, Radar and Antennas in Six Languages

English/American; French; Spanish; Italian ; Dutch and German. Compiled and arranged on an English Alphabetical Base by W. E. Clason. Pp. viii +760. (Amsterdam : Elsevier Publishing Company ; London: Cleaver-Hume Press, Ltd., 1955.) $120 s$.

7 HIS is a most welcome addition to the reference books dealing with the recent applications of radio to radar and television techniques. Most workers in these fields find that, sooner or later, they have to discuss progress with their contemporaries in other countries or to read accounts of scientific and technical progress in other languages. The advances made during the past decade have been so revolutionary that most existing technical dictionaries are in many respects obsolete. Moreover, as science becomes more and more international, there is a growing need for multilingual dictionaries. It was with the view of meeting this need that the publishers planned a series of polyglot technical dictionaries, of which this one is the first, dealing with television and radar and the aerials used with both these applications. In planning this dictionary, the author and publisher have been guided by certain principles proposed by Unesco. The object of these principles is to ensure that each dictionary produced according to them shall fit into place in a pattern which, it is hoped, may progressively extend over all inter-related fields of science and technology and cover all necessary languages.

The arrangement and lay-out of this volume have clearly been the subject of much serious thought and experiment. At each double-page opening the reader is presented with, on one side, the English term or phrase in bold-face type, and a brief but adequate definition of this term; while on the other page are given the equivalent terms in each of five other languages--French, Spanish, Italian, Dutch and German-the gender of the term being indicated in each case. Each definition is numbered at the extreme left and right, respectively, of the double page. The basic language being English/American (according to the publishers), these definitions are arranged in alphabetical order. But the book is completed by five alphabetical indexes for the other languages mentioned, giving the numerical reference to the English term. Where the usage of the 'English' term differs in Britain and in the United States, this is made quite clear, and the appropriate cross-indexing is included. It is interesting to note that a number of the terms are followed by the italic letters $s l$, meaning slang or code-names, which are or have been in common use among those engaged in the development and application of radar in Great, Britain and the United States. Some, but not all, of these have been found to have equivalent terms in other languages.

The bibliography appended to the volume shows that full use has been made of the glossaries and technical dictionaries published in various countries, including those of the British Standards Institution, the American Standards Association and the International Civil Aviation Organization.

The publication of this work is very opportune at the present time in view of the growing importance of the exploitation of radio aids to aerial and marine navigation, and the need to facilitate the international exchange of programmes in the further advance of television. The production of the book is excellent; it is of a handy size, in a semi-flexible binding, and provided with a convenient thumb. index to the different languages. It should be readily available for immediate reference by every scientist and engineer engaged in the fields of television, radar and the associated antenna systems.

R. L. Sмiтh-Rose

\section{SPECTROSCOPY AT CENTIMETRE WAVE-LENGTHS}

Microwave Spectroscopy

By Prof. C. H. Townes and A. L. Schawlow. (International Series in Pure and Applied Physics.) Pp. xviii +698. (London: McGraw-Hill Publishing Company, Ltd., 1955.) 90s. $6 d$.

Spectroscopy at Radio and Microwave Frequencies By Dr. D. J. E. Ingram. Pp. xii +332. (London: Butterworths Scientific Publications, 1955.) 45s.

VICROWAVE spectroscopy may in some respects radio-frequency measurements and of infra-red spectroscopy to the spectral region lying between $3 \times 10^{9} \mathrm{c} / \mathrm{s}$. and $3 \times 10^{11} \mathrm{c} . / \mathrm{s}$. (that is, to wavelengths between $10 \mathrm{~cm}$. and $1 \mathrm{~mm}$.). The techniques of measurement may be derived from each of these 